\title{
MANOMETRIA ESOFÁGICA: limpeza e desinfecção do equipamento com glutaraldeído. Protocolo do Hospital de Clínicas de Porto Alegre, RS.
}

\author{
Suzana MÜLLER ${ }^{1}$, Antônio Carlos GRUBER ${ }^{2}$, \\ Heloísa H. K. HOEFEL ${ }^{3}$ e Sérgio Gabriel Silva de BARROS ${ }^{4}$
}

RESUMO - Racional - A necessidade de desinfecção e esterilização apropriada de materiais reutilizáveis, com a finalidade de evitar infecções cruzadas, tem sido enfatizada por inúmeras publicações. Assim como os endoscópios, os cateteres de manometria esofágica são considerados materiais semicríticos e devem estar livres de microorganismos. Objetivo Padronizar o processo de limpeza e desinfecção do material e equipamento de manometria esofágica no Serviço de Manometria do Hospital de Clínicas de Porto Alegre, RS, a fim de garantir a segurança dos pacientes na reutilização de materiais semicríticos, baseado em protocolos internacionais e de acordo com a Comissão de Controle de Infecção Hospitalar do Hospital de Clínicas de Porto Alegre. Material e Métodos - Foi utilizado detergente enzimático para a limpeza do cateter, seguido de imersão em glutaraldeído a $2 \%$ por 20 minutos para desinfecção de alto nível. O reservatório foi armazenado limpo e seco. Foram consultados os protocolos utilizados pelo Hôpital Edouard Herriot, Lyon, França e pela Sociedade Americana de Enfermeiras do Trato Gastrointestinal e Associados. Conclusões - A desinfecção de alto nível com glutaraldeido a $2 \%$, precedido de limpeza com detergente enzimático, constitui técnica segura e simples para evitar transmissão de infecções cruzadas no material e equipamento de manometria esofágica, devendo ser realizada após cada procedimento. Os transdutores, pelas suas características, devem ser reesterilizados em óxido de etileno a cada 6 meses. Os profissionais envolvidos nesta área devem trabalhar conjuntamente com a Comissão de Controle de Infecção Hospitalar, conhecer normas e portarias do País e manterem-se atualizados quanto a novos processos de esterilização de materiais oferecidos no mercado.

DESCRITORES - Manometria, instrumentação. Desinfecção. Esterilização. Glutaral.

Trabalho realizado no Hospital de Clínicas de Porto Alegre - HCPA - da Universidade Federal do Rio Grande do Sul, Porto Alegre, RS.

Enfermeira do Centro Cirúrgico Ambulatorial do HCPA. Mestranda do Programa de Pós-Graduação em Gastroenterologia e Ciências Aplicadas à Gastroenterologia da Faculdade de Medicina da Universidade Federal do Rio Grande do Sul - FAMED, UFRGS.

Médico do HCPA. Doutorando do Programa de Pós-Graduação em Gastroenterologia e Ciências Aplicadas à Gastroenterologia, FAMED, UFRGS

Professora da Escola de Enfermagem da UFRGS. Chefe do Serviço de Controle de Infecção Hospitalar do HCPA.

Professor Adjunto, Departamento de Medicina Interna. Coordenador da Comissão de Pós-Graduação da FAMED, UFRGS. Médico do Serviço de Gastroenterologia e Chefe do Laboratório de Fisiologia Digestiva do HCPA.

Endereço para correspondência: Dr. Sérgio Gabriel Silva de Barros - Programa de Pós-Graduação em Medicina: Gastroenterologia - Rua Ramiro Barcelos, $2400,2^{\circ}$ andar - 90035 003 - Porto Alegre, RS. e-mail: ppgastro@vortex.ufrgs.br 


\section{INTRODUÇ̃̃O}

A necessidade de desinfecção e esterilização apropriada de materiais reutilizáveis tem sido enfatizada por inúmeras publicações, documentando risco para infecção após reprocessamento impróprio de itens de cuidados ao paciente ${ }^{(1,19)}$. Assim como os endoscópios, os cateteres de manometria são considerados materiais semicríticos, pois entram em contato com as membranas mucosas e devem estar livres de microorganismos, principalmente em suas formas vegetativas ${ }^{(12,13,14)}$.

Algumas definições são necessárias para melhor compreensão do texto a seguir. São elas:

Esterilização é a eliminação completa ou a destruição de todas as formas de vida microbiana. É alcançado por processos físicos e/ou químicos.

Desinfecção descreve processo que elimina vários ou todos os microorganismos patogênicos, com exceção de esporos bacterianos e prions.

O Center for Diseases Control (CDC), em Atlanta, GA, EUA, reconhecido internacionalmente por sua excelência, utiliza a definição de três tipos de desinfecção ${ }^{(13)}$ : a desinfecção de alto nível pode destruir todos os microorganismos, com exceção de alta concentração de esporos bacterianos; a desinfecção de nível intermediário inativa Mycobacterium tuberculosis, bactérias vegetativas, a maioria dos vírus e fungos, mas não elimina esporos bacterianos; a desinfecção de baixo nível não elimina microorganismos resistentes, como bacilo da tuberculose ou esporos bacterianos.

As membranas mucosas intactas são geralmente resistentes à infecção por esporos bacterianos comuns, mas são suscetíveis a outros microorganismos, como o bacilo da tuberculose e vírus ${ }^{(13)}$. Os itens semicríticos, como o equipamento para manometria esofágica aqui descritos, geralmente requerem desinfecção de alto nível, obtido através de desinfetantes químicos ${ }^{(14)}$. O glutaraldeído a $2 \%$ é o desinfetante mais largamente utilizado para desinfecção de alto nível em materiais semicríticos ${ }^{(20)}$. O tempo de utilização para os endoscópios digestivos ainda é discutido, variando de 10 a 45 minutos entre diferentes autores. Aceita-se, entretanto, que o tempo mínimo de 20 minutos seja necessário para a eliminação do

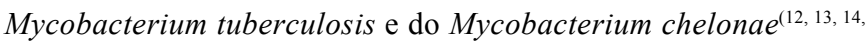
17). Recente publicação, entretanto, mostrou que após o processo normal de limpeza, incluindo limpeza manual (retirando, portanto, a contaminação progressiva e resíduos de proteínas), exposição ao glutaraldeído, uso do álcool $70^{\circ}$ e secagem dos endoscópios, a redução de 6-log das micobactérias foi alcançada após uma exposição por 10 minutos $^{(10)}$.

Esta aceitação se deve ao fato de que a maioria dos trabalhos em situações de uso neste período de tempo, demonstra a eliminação dos microorganismos conhecidos como mais resistentes à ação dos desinfetantes.
A Sociedade Brasileira de Enfermagem em Endoscopia Gastrointestinal (SOBEEG) lançou em 1999 o "Manual de Reprocessamento de Limpeza e Desinfecção de Aparelhos e Acessórios Endoscópicos"(9), com apoio da Sociedade Brasileira de Endoscopia Digestiva (SOBED), sendo o primeiro passo da enfermagem para a padronização nacional do processo de limpeza e desinfecção dos endoscópios e acessórios, seguindo as normas brasileiras de métodos e produtos químicos para limpeza, desinfecção e esterilização de artigos e áreas em estabelecimentos de saúde no país.

A portaria do Ministério da Saúde n 930 (D.O.U. de 27/08/92) que atualizava conceitos e normas do controle de infecção hospitalar, relaciona, no seu anexo $\mathrm{V}$, esses métodos. Não há detalhes de prioridades, opções e considerações quanto ao tipo de carga microbiana depositada na superfície, concentração de produtos, tempo de exposição, validade de uso e outros fatores relacionados ${ }^{(2)}$. Segundo a antiga Portaria $n^{\circ} 15$ (D.O.U. de 23/08/88) os artigos semicríticos devem ser expostos ao glutaraldeído $2 \%$ por 30 minutos a fim de atingir a desinfecção de alto nível ${ }^{(3)}$.

As portarias substitutivas subseqüentes não definem o tempo necessário para o tratamento dos diferentes materiais. No entanto, já está sendo elaborado pelo Ministério da Saúde orientação básica estipulando os períodos de exposição. Na literatura nacional não há adesão explícita identificada na literatura pesquisada à indicação de 30 minutos recomendada na Portaria $930^{(7,8,15)}$.

Os cateteres de manometria são mais simples que os endoscópios, entretanto, possuem diversos canais, entram em contato com secreções mucosas, podendo inclusive, provocar lesões de mucosa com pequenos sangramentos durante a sua introdução. Estes cateteres sendo reutilizados em múltiplos pacientes, necessitam adequada e segura desinfecção. Além do cateter, cuidados especiais também devem ser tomados com o sistema de infusão microcapilar.

\section{Objetivos}

A inexistência de literatura brasileira sobre este assunto específico e a escassez de bibliografia internacional, estimularam o desenvolvimento de um protocolo de limpeza e desinfecção do material de manometria esofágica, a partir de conhecimentos práticos adquiridos no Hospital de Clínicas de Porto Alegre (HCPA), de estágio realizado no "Hôpital Edouard Herriot", Lyon, França, de intercâmbio de informações com a Sociedade Americana de Enfermagem Gastrointestinal e Associados (SGNEA), além de informações dos fabricantes e fornecedores de materiais para manometria. A rotina adaptada para o laboratório foi discutida com os usuários do laboratório, respeitando os princípios de limpeza e desinfecção, preconizados pelo CDC (Center for Disease Control) e pela Comissão de Controle de Infecção Hospitalar (CCIH-HCPA). 


\section{MATERIAL E MÉTODOS}

\section{Sistema de manometria esofágica por infusão microcapilar com água}

$\mathrm{O}$ equipamento inclui o sistema de manometria por cateter, transdutores, o fisiógrafo e o computador.

O cateter ou sonda esofágica, especialmente desenhado, é longo e flexível. O sistema de infusão por água consiste de um cateter composto por pequenos tubos capilares, um reservatório de água e uma bomba de infusão hidráulica acoplados a transdutores externos. Os pequenos tubos capilares possuem diâmetro interno de $0,8 \mathrm{~mm}$ e um pequeno orifício de abertura. $\mathrm{O}$ cateter comumente utilizado possui oito tubos capilares recobertos por uma cobertura plástica com diâmetro total de $4,5 \mathrm{~mm}$ para adultos e $3,5 \mathrm{~mm}$ nos pediátricos ${ }^{(5,6,18)}$. Os oito orifícios deste cateter são dispostos com as quatro saídas distais ou afastados $1 \mathrm{~cm}$ ou no mesmo nível, e com orientação radial de 90 graus. Os quatro sensores proximais são $5 \mathrm{~cm}$ afastados e também orientados radialmente. A bomba de infusão perfunde os tubos capilares com água numa média de $0,5 \mathrm{~mL} / \mathrm{min}$. Quando a saída do cateter está ocluída (exemplo, por uma contração muscular), a pressão na coluna de água aumenta e é transmitida para os transdutores.

O fisiógrafo ou computador recebe o sinal elétrico dos transdutores e produz um gráfico para leitura e interpretação(5, 6, 19) (Figura 1).

$\mathrm{O}$ exame não necessita de nenhuma manipulação estéril, mas os pacientes podem ser portadores de diferentes vírus (HBV, HBC, HIV), fungos e bactérias.

O risco de transmissão de infecções através de procedimentos depende de três fatores:

1. Exposição do material a microorganismos;

2. Procedimentos de limpeza e desinfecção;

3. Características do material a ser utilizado ${ }^{(17)}$.

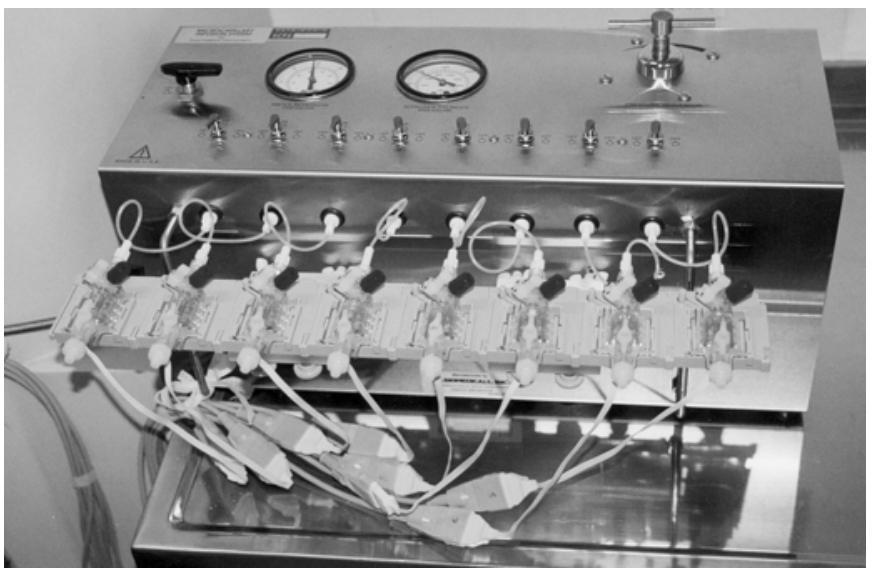

FIGURA 1 - Sistema de infusão microcapilar com cateter de oito canais conectado aos transdutores
A transmissão de infecção pode ser categorizada de paciente para paciente ou do ambiente para paciente. Durante o exame, o material pode ser contaminado pelas secreções do paciente. A contaminação do ambiente pode se dar através da limpeza com soluções previamente contaminadas ${ }^{(17)}$.

Glutaraldeído $2 \%(1,11,13,14)$

Esta substância é um dialdeído saturado que se torna ativo após alcalinização em pH 7,5-8,5, tornando a solução esporicida. Uma vez ativada a solução, tem vida útil para 14 ou 28 dias (dependendo da apresentação), com atividade antimicrobiana de largo espectro. É capaz de eliminar bactérias vegetativas em aproximadamente 2 minutos, fungos e vírus em 10 minutos, M. tuberculosis em 20 minutos e esporos de Bacillus e Clostridium em 3 horas. Sua atividade pode ser afetada pela diluição, temperatura, e presença de matéria orgânica. Os estudos na literatura sugerem que uma concentração mínima de $1 \%$ a 1,5\% seja necessário para a desinfecção de alto nível, sendo necessária concentração de $2 \%$ para a eliminação das micobactérias.

A solução de glutaraldeído agrega proteínas, tornando indispensável a limpeza cuidadosa do instrumental para a remoção dos resíduos antes da desinfecção. A desvantagem é o efeito tóxico, irritativo principalmente à mucosa respiratória quando utilizado em ambientes com baixa ventilação.

\section{Ácido peracético}

Tem sido proposto, recentemente, como alternativa ao glutaraldeído.

É resultante da mistura em equilíbrio de ácido acético, peróxido de hidrogênio e água, sendo decomposto ao final em ácido acético e água, e seguro do ponto de vista ocupacional.

Solução de amplo espectro de ação, sendo viruscida, bactericida, fungicida e esporicida a baixas concentrações ${ }^{(11,20)}$.

Como desvantagem, apresenta corrosividade de metais em altas concentrações. Como a corrosividade é específica para cobre, latão, bronze, aço e ferro galvanizado é necessário verificar junto aos fabricantes quanto a existência de um destes componentes no material que se deseja tratar. A existência de acrílico impuro também deve ser investigada já que a compatibilidade citada é com PVC, policarbonato e outros polímeros. A diluição e adição de anticorrosivos à solução torna viável a utilização para tratamento de endoscópios.

Os riscos à saúde, como queimaduras e inalação de vapores, estão associadas a concentrações mais altas do que as comumente usadas como germicidas $(0,2 \%$ e $0,35 \%)$.

A utilização do ácido peracético é vista como alternativa ao glutaraldeído já que este último apresenta diversos aspectos relacionados à saúde como inalação de vapores, irritação ocular e por não ser biodegradável. No entanto, ainda são levantadas dúvidas quanto à ação corrosiva pelo ácido peracético nos instrumentos de endoscopia, principalmente pelo histórico ainda pequeno de uso desta solução ${ }^{(8)}$. 
Müller S, Gruber AC, Hoefel HHK, Barros SGS. Manometria esofágica: limpeza e desinfecção do equipamento com glutaraldeído. Protocolo do Hospital de Clínicas de Porto Alegre, RS.

Teria vantagens, adicionalmente, por remover resíduos em microcompartimentos do instrumental de difícil acesso.

\section{QUADRO 1 - Cuidados com o equipamento de manometria}

Os procedimentos de limpeza e desinfecção devem ser realizados com equipamentos de proteção individual quando utilizado o glutaraldeído, a fim de evitar infecções e acidentes ao trabalhador. O uso de luvas de borracha, máscara de carvão ativado, avental de mangas longas e óculos protetores são indispensáveis para a manipulação com o glutaraldeído. Sua toxicidade é alta, podendo causar reações alérgicas respiratórias e por contato $^{(6,17)}$

\section{Desinfecção do cateter}

Recomenda-se a desinfecção prévia no início do dia, antes do primeiro exame, com um processo de 10 minutos em glutaraldeído 2\%. Enxaguar abundantemente, lavando os diferentes canais. A secagem não se faz necessária para os cateteres que serão utilizados durante o turno de trabalho ${ }^{(9,20)}$. A Fig. 2 mostra a desinfecção do cateter.

- Após o cateter ter sido retirado do paciente:

- Lavar externamente o cateter em detergente enzimático com auxílio de uma gaze;

- Introduzir a solução de detergente nos diferentes canais, com auxílio de uma seringa de 5 ou $10 \mathrm{~mL}$ (seringas com maior volume geram pressões excessivas com estresse e tensão nos canais);

- Enxaguar em água corrente durante 5 minutos;

- Imergir em solução de glutaraldeído $2 \%$, introduzir esta solução nos diferentes canais com auxílio da seringa;

- Manter imerso em solução de glutaraldeído por 20 minutos;

- Enxaguar com água corrente, injetar água com baixa pressão nos diferentes canais;

- Injetar $5 \mathrm{~mL}$ de álcool $70^{\circ}$ nos canais para permitir melhor secagem;

- Secar externamente com um tecido macio;

- Secar cada canal com ar comprimido à baixa pressão (máximo 10 mm Hg para evitar pressão e estresse);

- Estocar em embalagem apropriada, limpa, tipo grau cirúrgico.

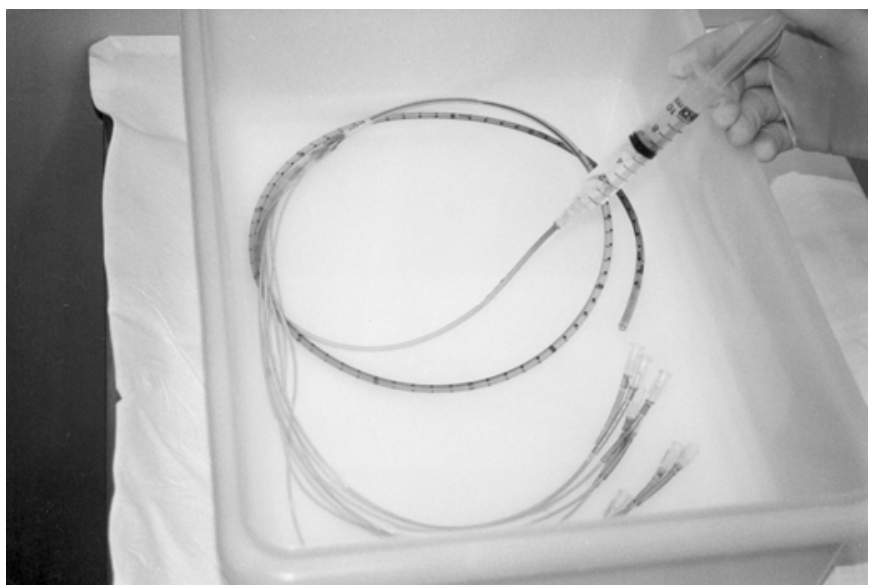

FIGURA 2 - Desinfecção do cateter. Introdução do glutaraldeído 2\% nos canais com auxílio de uma seringa.
QUADRO 2 - Cuidados com o sistema para infusão microcapilar

\section{Reservatório de água}

- Utilizar somente água estéril ou destilada (Fig.3);

- Lavá-lo com água estéril antes do primeiro uso, pois não é utilizado nenhum produto desinfetante ao ser armazenado;

- Remover a água após o uso diário, desconectando-o do sistema hidráulico, lavá-lo com detergente enzimático;

- Enxaguar com água corrente;

- Secar com tecido macio;

- O reservatório deve ser armazenado desconectado, vazio e seco até o próximo exame;

- As válvulas na máquina devem ser mantidas abertas a fim de remover a água de dentro do sistema;

- Drenar a água dos conectores;

- Limpar externamente o sistema com água e sabão neutro uma vez por semana;

- Os transdutores devem ser removidos a cada 6 meses para reesterilização em óxido de etileno, permitindo avaliação destes. Antes de encaminhar para a reesterilização, secar com baixa pressão (máximo $5 \mathrm{~mm} \mathrm{Hg}$ para evitar danos) $)^{(9,20)}$.

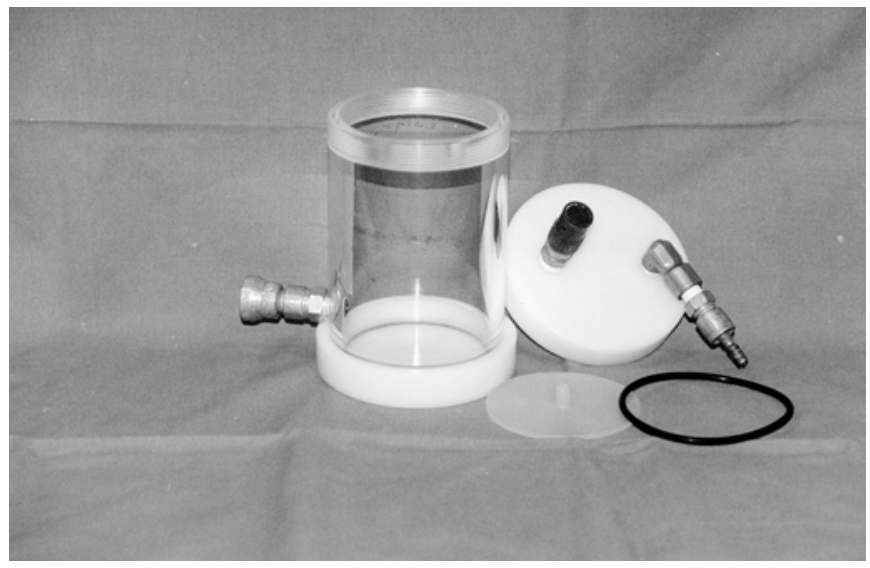

FIGURA 3 - Reservatório de água estéril, limpo e seco, em condições de ser armazenado

\section{Controle de qualidade da desinfecção}

De acordo com o "Groupement des Infirmières et Infirmiers pour la Formation en Endoscopie" da França *, devem ser realizados testes laboratoriais dos cateteres de manometria, do reservatório de água e do circuito hidráulico a cada 4 meses. Já a "Society of Gastroenterology Nurses and Associates" (SGNA) ${ }^{(16)}$, dos EUA, não preconiza estes testes, pois o grau de contaminação é baixo ou inexistente e, até o momento, não tem sido relatado qualquer caso de transmissão de infecção através da manometria esofágica. No HCPA estes testes não são

Hôpital Edouard Herriot. GIFE - Groupement des Infirmières et d'Infirmiers pour la Formation en Endoscopie. XVII ${ }^{\text {emes }}$ Journées Regionales de Formation. Lyon, France: 1997. 232p. [não publicado]. 
Müller S, Gruber AC, Hoefel HHK, Barros SGS. Manometria esofágica: limpeza e desinfecção do equipamento com glutaraldeído. Protocolo do Hospital de Clínicas de Porto Alegre, RS.

realizados. A reesterilização em óxido de etileno dos transdutores a cada 6 meses, permitiu revisá-los e garantir seu bom funcionamento. As dificuldades que se tinham com as conexões de engate rápido do reservatório de água foram solucionadas com o suporte técnico do serviço de engenharia e manutenção do HCPA, permitindo a limpeza e secagem para seu armazenamento. O trabalho conjunto com a CCIH é de extrema importância a fim de assegurar procedimento correto e seguro.

\section{CONCLUSÕES}

A desinfecção de alto nível com glutaraldeído $2 \%$, precedido de limpeza com detergente enzimático, constitui técnica segura e simples para evitar a transmissão de infecções cruzadas no material e equipamento da manometria esofágica. Este procedimento deve ser realizado após cada exame. A utilização do óxido de etileno se faz necessário para materiais mais específicos como os transdutores.

Os métodos utilizados na França e Estados Unidos serviram de suporte para a definição do protocolo a ser implantado no laboratório. $\mathrm{O}$ trabalho em conjunto com a (CCIH-HCPA) assegurou a viabilidade desta técnica.

Os profissionais envolvidos devem conhecer normas e portarias do país e manterem-se atualizados quanto a novos processos e materiais de esterilização.

Müller S, Gruber AC, Hoefel HHK, Barros SGS. Esophageal manometry: equipment cleaning and disinfection with glutaraldehyde. Arq Gastroenterol 2001;38(4):276-280.

ABSTRACT - Background - Many publications have emphasized the need of proper cleaning, disinfection and sterilization process for reused materials intended to prevent cross infections. As the endoscope the esophageal manometry catheters are considered as semicritical materials and must be free of microrganisms. Aim - To standardize the esophageal manometry materials cleaning and disinfection process to guarantee the safety of patients when reusing semicritical materials. It was based on international protocols and according to recommendations of the Hospital Infection Control Commission of the "Hospital de Clínicas de Porto Alegre", Porto Alegre, RS, Brazil. Materials and Methods - Enzymatic detergent was used for catheter cleaning, followed by immersion with $2 \%$ glutaraldehyde solution during 20 minutes for high-level disinfection. The water reservatory was kept clean and dry to prevent microorganisms proliferation. Conclusions: The high level disinfection with $2 \%$ glutaraldehyde, preceded by enzymatic detergent cleaning, is a safe and simple technique that avoids cross infection in the esophageal manometry equipment. This care must be taken after each manometric procedure. The transducers must be resterilized in ethylene oxide. The professionals of this area must work in concordance with the Hospital Infection Control Commission, being acquainted with the country laws and regulations and keeping sterilizing process and materials updated.

HEADINGS - Manometry, instrumentation. Disinfection. Sterilization. Glutaral.

\section{REFERÊNCIAS BIBLIOGRÁFICAS}

1. Belgique. Ministére de la Santé Publique et de l'Environnement. Conseil Supérieur d'Hygiène [online]. Entretien du materiel endoscopique et prevention des infections. Bruxelles; Juin 1996. [citado 2001 Mar 8]. Disponível em: http/ /www.md.ucl.ac.be/didac/hosp/cours/endos.htm

2. Brasil. Ministério da Saúde. Coordenação de Controle de Infecção hospitalar. Processamento de artigos e superfícies em estabelecimentos de saúde. 2. ed. Brasília: 1994.

3. Brasil. Ministério da Saúde. Secretaria Nacional de Vigilância Sanitária. Portaria $\mathrm{n}^{\circ}$ 15. Diário Oficial da União. Brasília: 23 de agosto de 1988.

4. Brasil. Ministério da Saúde. Portaria $n^{\circ} 930$. Diário Oficial da União. Brasília: 27 de agosto de 1992.

5. Castell J, Dalton C. The esophageal motility laboratory: materials and equipment In: Castel DO, editor. Esophageal motility testing. 2. ed. Englewood Cliffs, New Jersey: Prentice Hall; 1994. p.27-34.

6. Castell JA. Esophageal manometry. In: Castell DO, editor. The esophagus. 2. ed New York: Little, Brown; 1995. p.133-52.

7. Ferraz EM. Infecção em cirurgia. 2. ed. Rio de Janeiro: MEDSI; 1997.

8. Hoefel H. Controle de infecções em instituições de saúde. [S.1.]: 2000. Disponível em: http//www.cih-com.1997br.

9. Jesus IMN, Benedito G, Brandão MA, Collete F, Müller S, Fanes L. Manual de reprocessamento de limpeza e desinfecção de aparelhos e acessórios endoscópicos. Salvador, BA: Sociedade Brasileira de Enfermagem em Endoscopia Gastrointestinal - SOBEEG; 1999.

10. Kovacs BJ, Chen YK, Kettering JD, Aprecio RM, Roy I. High-level disinfection of gastrointestinal endoscopes: are current guidelines adequate? Am J Gastroenterol 1999;94:1546-50.
11. McDonnell G, Russel D. Antiseptics and disinfectants activity, action and resistance. Clin Microbiol Rev 1999;1:147-79.

12. Petersen, Bret T. Gaining perspective on reprocessing of GI endoscopes Gastrointest Endosc 1999;50:287-91.

13. Rutala WA. APIC - Association for Professionals in Infection Control and Epidemiology. Guideline for selection and use of disinfectants. Am J Infect Control 1996;24:313-42.

14. Rutala WA, Weber DJ. Disinfection of endoscopes: review of new chemica sterilants used for high-level disinfection. Infect Control Hosp Epidemiol 1999;20:69-76.

15. Scarpitta CRM. Limpeza e desinfecção de artigos hospitalares. In: Rodrigues E, editor. Infecções hospitalares: prevenção e controle. São Paulo: Sarvier; 1997. p.471-520.

16. Society of Gastroenterology Nurses and Associates. California, EUA www.sgna.org ou http://www.sgna.org/endoscope.html

17. Spach DH, Silverstein FE, Stamm WE. Transmission of infection by gastrointestina endoscopy and bronchoscopy. Ann Intern Med 1993;118:117-28.

18. Synectics Medical. PC Poligraf HR. General informations. São Paulo: Micronal (Publicação comercial). (Disponível na página da Internet http:// www.micronal.com.br/)

19. Webmaster. Medical Reference Library. Health answers. Esophageal manometry. Webmaster@healthanswers.com

20. Working Party of the British Society of Gastroenterology. Cleaning and disinfection of equipment of gastrointestinal flexible endoscopy: interim recommendations of a Working Party of the British Society of Gastroenterology. Gut 1988;29:1134-51. 